$\begin{array}{ll} & \text { Etnográfica } \\ \text { etnográfica } & \text { Revista do Centro em Rede de Investigação em }\end{array}$

Antropologia

vol. 15 (1) | 2011

Vol. 15 (1)

\title{
Por onde anda o sentimento de insegurança? Problematizações sociais e científicas do medo à cidade
}

Where is the feeling of insecurity? Social and scientific questions concerning the fear of the city

\section{Luís Fernandes e Ximene Rêgo}

\section{(2) OpenEdition}

\section{Journals}

\section{Edição electrónica}

URL: https://journals.openedition.org/etnografica/869

DOI: 10.4000/etnografica.869

ISSN: 2182-2891

\section{Editora}

Centro em Rede de Investigação em Antropologia

\section{Edição impressa}

Data de publição: 1 fevereiro 2011

Paginação: 167-181

ISSN: 0873-6561

\section{Refêrencia eletrónica}

Luís Fernandes e Ximene Rêgo, «Por onde anda o sentimento de insegurança? Problematizações sociais e científicas do medo à cidade», Etnográfica [Online], vol. 15 (1) | 2011, posto online no dia 23 outubro 2011, consultado o 11 fevereiro 2022. URL: http://journals.openedition.org/etnografica/869 ; DOI: https://doi.org/10.4000/etnografica.869

\section{(c) (†) 8}

Etnográfica is licensed under a Creative Commons Attribution-NonCommercial 4.0 International License. 


\section{Por onde anda o sentimento de insegurança? Problematizações sociais e científicas do medo à cidade}

\section{Luís Fernandes e Ximene Rêgo}

O debate público adotou as questões da (in)segurança, fazendo fixar imagens do que são o crime e a violência em Portugal. Essas imagens estão repletas de ambiguidade, não só pelos próprios paradoxos que a comunidade científica já mostrou serem constitutivos do sentimento de insegurança, mas igualmente pela profusão das falas dos diversos atores sociais em cena - da comunicação social às instâncias de controlo formal. Aqui, seguimos a rotação operada do medo à cidade, com o surgimento dos perigos modernos, para o sentimento de insegurança, tomado como objeto das ciências sociais. Analisamos, depois, dois determinantes da sua construção: os seus elementos ecossociais - a partir de um estudo em curso no Centro do Porto; e a sua dimensão mediática a partir de casos recentes fortemente mediatizados. Espera-se, desta forma, contribuir para reduzir o grau de ambiguidade que tem marcado a expressão pública deste objeto.

PALAVRAS-CHAVE: sentimento de insegurança, crime, comunicação social, etnografia.

“Não há grande exagero se dissermos que raro é o dia em que os jornais não trazem a notícia de um ou dois homicídios. Quanto a roubos, sempre se roubou, mesmo quando os nossos costumes eram brandos. Carteiras, residências, automóveis estacionados. Mas, na atualidade, assaltam-se, de caçadeira em punho, agências bancárias, farmácias, gasolineiras - e pratica-se o carjacking. O que nos fez passar de um "povo de brandos costumes" a um povo que rapidamente se habituou a conviver com a violência?" (Andrade 2008). 
De acordo com os rituais públicos discursivos acerca da (in)segurança, somos um país de baixa criminalidade, mas com um crescente sentimento de insegurança - o que nos tornaria um povo irracionalmente medroso. ${ }^{1}$ Houve mesmo notícias que nos deram como o nono país mais seguro do mundo e o terceiro da Europa com criminalidade mais baixa. ${ }^{2}$ Apesar disso, esta entidade - a da nossa intranquilidade coletiva -, sobretudo nos grandes espaços urbanos, aparentemente não pára de crescer. A acreditar na esfera mediática, em particular na sua modalidade televisiva, vivemos num país assolado por ondas de criminalidade violenta - o que também não joga com a ideia de sermos um país de brandos costumes...

"Os valores apurados em 2007, quer os referentes à criminalidade geral, quer, sobretudo, os relativos à criminalidade violenta e grave, contrariam uma tendência inversa que parece vir a registar-se ao nível do sentimento de insegurança e do medo do crime, na nossa sociedade" (MAI 2008a: 1).

Os relatórios de Segurança Interna, publicados pelo Ministério da Administração Interna (MAI), dizem respeito à criminalidade registada, deixando de fora as cifras negras. Estes relatórios, que são tomados muito a sério e que são, durante dias, largamente mediatizados, espelham, também eles, um ritual anual: o de fixar as imagens do que estariam a ser a violência, o crime e a insegurança em Portugal. No entanto, não é suficientemente sublinhado o facto de esta imagem assentar numa base que é parcial. Com efeito, apenas cerca de $40 \%$ dos crimes contra as pessoas e 33\% dos crimes contra a propriedade são reportados às polícias; se analisássemos mais finamente, por exemplo, por tipo de crime dentro de cada grande categoria ou por tipo de denunciante, veríamos uma enorme variação: as pessoas de baixos rendimentos, os jovens de ambos os sexos e os homens denunciam menos, verificando-se o mesmo com os crimes em que vítima e ofensor se conhecem (Skogan 1995).

Estas imagens, para se aproximarem daquilo de que querem ser retrato, deveriam ser combinadas com as que resultam da aplicação de outros tipos de instrumentos, preferencialmente realizadas por organismos independentes.

l O recurso a estatísticas oficiais da criminalidade como estratégia única para definir políticas de segurança ou conduzir estudos científicos, sem a utilização de outros instrumentos complementares de medição, apresenta-se sempre muito polémico. A comparação internacional dos números do crime é extremamente complexa: os países variam grandemente na maneira de organizar os sistemas policial e judicial, de definir os conceitos legais e de recolher e apresentar os dados estatísticos. Desta forma, a ausência de uniformidade nas definições de ofensa, na utilização de instrumentos de medição e nas metodologias de recolha de dados torna o esforço de comparação muito difícil (WODC 2003, 2006; Tavares e Thomas 2007).

2 Dados divulgados pelo Economist Intelligence Unit, do grupo da revista The Economist, em 30 de maio de 2008. A notícia deu origem a um artigo de opinião no site do Ministério da Administração Interna (MAI 2008b), bem como a uma ampla divulgação na comunicação social. 
Doutro modo, não temos com que contrastar a versão oficial dos acontecimentos, resultante dos números fornecidos pelo MAI. Este diz-nos que a criminalidade grave, este ano, diminuiu, enquanto a esfera mediática se compraz em dizer-nos que ela não pára de aumentar. Afinal, perguntamo-nos todos, o crime aumenta ou diminui? E que tipo de crime aumenta e que tipo de crime diminui? Porque há-os de muitos tipos e a sua gravidade é diferencial, tal como o receio que infundem. E o sentimento de insegurança está mesmo a expandir-se? Se assim é, cresce em quem? Em todos igualmente? Eis-nos, portanto, a mover-nos num terreno pleno de ambiguidades.

\section{DO MEDO À CIDADE AO SENTIMENTO DE INSEGURANÇA}

Podemos situar a emergência dos medos que fazem hoje parte da experiência da vida nas grandes cidades já ao longo do século XIX. Vai-se nessa época desenvolvendo o conjunto de elementos que configuram as desordens e os perigos modernos, feitos do vagabundo, do pária, do ocioso, da meretriz, do delinquente de delito comum, do criminoso-louco, da criança que anda pelas ruas e que furta, mas também alimentado a partir das novas concentrações do operariado, constituindo as zonas que acantonavam as "classes perigosas". 3

Podemos dizer, portanto, que a cidade enquanto espaço predatório é já bem situável no Portugal oitocentista, começando a gerar um tipo de medos distinto daqueles que gerava quando era um espaço pré-moderno. Neste, o medo estava situado, por exemplo, nas epidemias que dizimavam a população, nas catástrofes que expressavam a ira divina e nos perigos cujo topos era, sobretudo, fora de portas - os lugares do medo eram os das encruzilhadas, os dos maus encontros dos caminhos nos percursos entre povoações.

Quanto ao sentimento de insegurança, é preciso avançar um século para o ver surgir - precisamente a distância que medeia entre a perceção dos novos perigos associados à grande cidade e a sua transformação em complexo de elementos discursivos omnipresentes no debate público, por via da esfera mediática, e na prática das ciências, por via da construção de um novo objeto de pesquisa. No caso português, temos de esperar pelo processo de modernização pós-25 de Abril - processo marcado por desequilíbrios como o duma intensa litoralização e metropolização, que em 30 anos concentrou cerca de 85\% da população numa faixa de 30 quilómetros de largura e aglomerou, em torno dos dois principais polos metropolitanos, Porto e Lisboa, quatro dos

3 Não nos deteremos sobre este processo histórico, em que as novas ameaças surgem associadas ao processo de industrialização e urbanização do período da Regeneração. Remetemos para João Fatela (1989) e para Maria João Vaz (1998, 2006), limitando-nos a assinalar que o lendário, mas bem real, José do Telhado é a nosso ver o símbolo da transição para a criminalidade moderna: ladrão de encruzilhadas, de caminhos e de quintas agrícolas, será preso por volta de 1850, pouco antes de se iniciar o período da Regeneração. 
dez milhões que vivem em território nacional. É precisamente nestas duas áreas metropolitanas que, de acordo com números repetidos ano após ano pelas autoridades, se concentrará grande parte da criminalidade de tipo aquisitivo. Analisámos já noutros trabalhos o impacte que as profundas transformações na forma urbana e nas suas dinâmicas populacionais, incluindo nestas o surgimento de novas franjas de marginalidade e novos atores vistos como ameaçadores, tiveram no aumento progressivo do sentimento de insegurança (Fernandes 2004, 2006).

Ora, demonstra-o a literatura especializada, é a pequena criminalidade de rua que alimenta, em grande parte, o medo à cidade, através da circulação do rumor sobre a sua proliferação. $\mathrm{O}$ crime estaria a invadir a vida quotidiana, mesmo quando não o vemos - mas vemo-lo através de uma espécie de contaminação, já que sentimos medo ao sentir que os outros o sentem. O rumor insecurizante foi invadindo as grandes cidades e, depois, as cidades de menor escala, à medida que se iam repetindo as notícias sobre assaltos um pouco por toda a parte: já não é apenas no cenário da grande cidade que os factos ocorrem, mas dum modo mais disseminado, desde montes alentejanos até pequenas dependências bancárias de vilas do interior, passando pelas gasolineiras em muitos pontos do país, numa espécie de demonstração mediática de que a criminalidade se dispersou e de que ninguém está seguro em parte alguma.

Dar-se-á com o medo do crime o mesmo movimento que vimos desenhar-se a propósito doutros objetos (o fenómeno droga ou, mais recentemente, a violência doméstica): à medida que ganha relevo no debate público e se torna elemento importante na contenda política, atrairá a atenção da comunidade científica. Depois dos EUA, depois da França ou da Espanha, também em Portugal o medo à cidade se irá transformando em sentimento de insegurança, um objeto problematizado no e pelo discurso das ciências sociais e humanas, reentrando assim rebatizado na linguagem ordinária dos meios de comunicação social e no falar comum da cidade. Dito doutro modo, passamos do medo à cidade, que é uma coisa dos leigos, para o sentimento de insegurança, que é uma coisa de especialistas...

Em Portugal, esta rotação opera-se ao longo dos anos 90. Primeiro, foram alguns órgãos de comunicação social, como o Público e o Expresso, a publicar extensos dossiês com títulos tão sugestivos como, por exemplo, "O atlas do medo". Pouco depois, a comunidade científica debruçava-se sobre o tema: o primeiro artigo terá saído em 1994 (Fernandes 1994). Em 1995, a Câmara Municipal do Porto (CMP) convida alguns investigadores da Universidade do Porto $^{4}$ a apresentar um projeto para estudar o medo à cidade, ao dar-se conta de que o sentimento de insegurança, entre os portuenses, tinha escalado para 
o segundo lugar do ranking das preocupações, logo a seguir ao problema da habitação. O que estaria a fazer o medo do portuense? A partir dos primeiros resultados, a CMP propôs estabelecer uma estrutura mais permanente que desse conta destes fenómenos. Acabou assim por ser criado o Observatório Permanente de Segurança, que efetuaria uma série de investigações entre 1996 e 2001. No final da década, apareciam as primeiras teses académicas que consagram o sentimento de insegurança como objeto no panorama das ciências sociais, cujos autores estavam ligados ou tinham colaboração com o observatório (Fonseca 1998; Machado 2004 [1999]; Santos 1997; Delgado 1998). Eis, portanto, a rotação do medo à cidade, que já andava à solta pelo espaço mediático, para o sentimento de insegurança, novo objeto científico. $^{5}$

Um dos aspetos que, logo de início, a investigação sobre o medo do crime mostrou foi o de que ele não tem uma leitura linear, como revela um conjunto de factos contraditórios entre si - os paradoxos da insegurança. Por exemplo, o atlas do medo numa cidade não coincide necessariamente com a criminalidade real, ou seja, os sítios onde as pessoas têm mais medo de ir ou de permanecer não são, normalmente, os sítios onde se manifesta mais criminalidade no dia a dia; o período mais insecurizante é o noturno, que é também aquele em que ocorrem menos delitos; temos grande receio de sermos vítimas de ofensas corporais - mas a grande maioria dos delitos é contra a propriedade e não contra as pessoas; alguns dos indivíduos que foram vitimados em delitos de rua exibem menos medo do que outros que nunca o foram; algumas das figuras de que temos mais medo têm uma presença discreta nos números que compõem o panorama criminal; e aqueles que as estatísticas oficiais do crime dizem ser os agressores (por exemplo, os jovens de periferia urbana desqualificada, herdeiros dos "delinquentes da working class") são, afinal, os mais vitimizados.

Os paradoxos da insegurança são múltiplos e poderíamos continuar a enunciá-los, tal como as hipóteses para a sua explicação e os estudos empíricos que os analisam. A sua persistência nas crenças comuns sobre os perigos da cidade, sobre quem são os agressores, as vítimas e os lugares do medo mostra com eloquência como as manifestações do sentimento de insegurança são um terreno pleno de ambiguidades.

5 Entre 1996 e 2001, o Observatório Permanente de Segurança produziu um conjunto de estudos de caráter interdisciplinar, com base numa equipa composta por psicólogos, sociólogos e arquitetos, refletindo duas vertentes de abordagem: medir a criminalidade através de inquéritos de vitimização e do tratamento estatístico da criminalidade registada pela PSP; compreender o modo como o sentimento de insegurança era construído e se exprimia na população (nesta vertente, refiram-se os seguintes trabalhos: "Percepções e figuras do medo na cidade do Porto" (Manita e Machado 1999); "Periferias urbanas, sentimento de insegurança e controlo social” (Neves e Fernandes 1999); "Insegurança e criminalidade nos media" (Manita 1997). 


\section{OS DETERMINANTES DO SENTIMENTO DE INSEGURANÇA}

Podemos nós, nas páginas que se seguem, dar um contributo para a redução das ambiguidades a que temos vindo a aludir? O medo à cidade, mostrámo-lo já noutro lugar, é um objeto fluido (Fernandes e Carvalho 2000): difícil de operacionalizar empiricamente (por exemplo, não é redutível ao crime e, portanto, à medição objetiva das taxas de criminalidade), tem forte variação individual, remetendo para o espaço psicológico do sujeito (o medo é uma emoção, o sentimento de insegurança é uma ressonância psicológica do modo como se percecionam certas realidades) e comporta-se como uma noção-contentor, onde se tem misturado uma diversidade de fenómenos e situações difíceis de relacionar entre si. O trabalho dos especialistas desta área tem de concentrar-se assim sobre a tentativa de operacionalizar dimensões que podem estar na base da construção do sentimento de insegurança. Debruçar-nos-emos a seguir sobre duas delas: as dimensões espacial e mediática.

\section{Pistas ecossociais}

"A rua de Trás, conheço... passei lá uma única vez, e foi com gente, só para conhecer... bom, aquilo não é muito seguro. Parece que, há uns anos largos atrás, aquilo tinha ali má vivência e, por conseguinte, saía dali dum bar ou dum café, não sei, muita gente já alcoolizada... dizem que aquilo nunca foi assim seguro. Mas sempre ouvi falar [da rua de Trás]. Fui com o meu marido só para conhecer aquela parte porque, de resto, há certas ruas que eu evito" [Ofélia, 75 anos, residente há 46 na rua do Almada].

Abordaremos a partir de agora elementos do ambiente urbano que a literatura tem vindo a relacionar com o sentimento de insegurança e que sugerem que a sua construção social enquanto objeto de inquietação resulta doutros elementos que não somente o crime. A noção de ambiente urbano não se limita a caraterísticas físicas ou estritamente espaciais, incluindo também caraterísticas ligadas aos aspetos sociais percecionados pelos residentes e pelos utilizadores da cidade. Os sinais de rutura física e social - as janelas partidas, o lixo por recolher, os graffiti, os edifícios degradados ou abandonados, a iluminação pública deficiente, as categorias problemáticas que habitam o espaço público... - inspiram receio, ao mesmo tempo que traduzem a impotência das instâncias de controlo. Estes sinais, de natureza material ou social, crónicos ou ocasionais, muitas vezes tidos como imprevisíveis, encontram-se diferentemente distribuídos no espaço e são sentidos como ameaça, insinuando ao mesmo tempo que as normas sociais não são observadas (Skogan 1990; Taylor 1989; Lagrange, Ferraro e Supancic 1992).

A decadência do espaço público, a erosão das normas, que se reflete no comportamento das figuras do receio, apresenta-se então como um sinal de rutura 
da ordem social local, pelo que o crime e a delinquência não serão fenómenos dissociáveis de outros problemas que afetam a comunidade; são antes percebidos como parte da rede alargada de problemas sociais. Daqui resulta que o medo tenha vindo crescentemente a tornar-se inseparável, não só do próprio crime e da desordem, mas também de outras dificuldades de ordem social e económica (Pain 2000).

Concretizemos agora para o nosso contexto pistas ambientais relacionáveis com o sentimento de insegurança. Apoiar-nos-emos, para esse exercício, numa investigação que temos em curso. ${ }^{6}$ Uma parte do trabalho de terreno decorre numa rua que faz costura entre a Baixa e a Zona Histórica do Porto (ao conjunto das duas áreas, chamamos Centro) e que traduz logo na sua toponímia aquilo que já noutros trabalhos chamámos "as traseiras da cidade" - chama-se rua de Trás. São espaços que resultam do fechamento mais ou menos súbito dos espaços abertos das ruas centrais, toda uma cidade que se desenrola fora das vistas mais imediatas do transeunte.

Porque escolhemos esta rua? Primeiro, ela ilustra alguns dos fenómenos, interligados, que vêm a ter lugar no Porto e que integram a agenda mediática e sociopolítica sempre que a cidade é problematizada. Falamos, primeiro, da desertificação e do envelhecimento da população. A tendência de perda de habitantes nos centros dos grandes aglomerados é típica do processo de metropolização em curso nas cidades que foram crescendo como polos industriais. Entre nós, é nitidamente o caso do Porto que, na última década, perdeu cerca de 30 mil habitantes e, nos últimos quarenta, cerca de 80 mil. O censo de 2001 indica que a freguesia da Vitória, a par das restantes três que compõem a Zona Histórica e que foram classificadas como Património Mundial pela UNESCO, está desertificada, envelhecida e em má posição em indicadores como os do emprego, escolaridade e rendimento. Entre 1960 e 2001, esta freguesia perdeu aproximadamente $66 \%$ da sua população, passando de cerca de 8000 para 2700 habitantes.

Depois, refiram-se as dinâmicas populacionais que marcam o lugar. A rua de Trás tem, nos seus residentes mais velhos, alguns que ainda testemunham diretamente o movimento de vinda para a cidade aquando do processo de industrialização/urbanização; por outro lado, algumas das casas devolutas refletem o movimento de ida para os bairros sociais. Esta dinâmica é sentida pelos próprios como algo de coercivo que os empurrou para as periferias, à medida que a Zona Histórica e a Baixa foram sendo valorizadas; no caso de haver recursos económicos suficientes, mas não suficientes para permanecer na

6 A pesquisa que tem vindo a ser desenvolvida na Zona Histórica do Porto integra e resulta de uma mais ampla - "A imagem predatória da cidade: uma etnografia urbana do medo", tese de doutoramento em Antropologia Urbana de Ximene Rêgo, coautora deste artigo -, cujo objeto é o sentimento de insegurança. 
área, a saída faz-se em direção ao Grande Porto. Se o processo de urbanização, fortemente intensificado a partir da Revolução Industrial, trazia vagas de gente para a cidade, o atual processo de metropolização deslocaliza-as dos centros e recoloca-as em rede pela área metropolitana, criando novas centralidades e complicando imensamente a leitura dos espaços urbanos. A descompressão demográfica dos centros tem, porém, inconvenientes: a terciarização é antagónica da função residencial, arrastando o esvaziamento dos espaços públicos a partir do fim da tarde e a degradação do parque habitacional que vai ficando semidevoluto.

Finalmente, há um conglomerado de expressões da desordem que parecem justificar a epígrafe acima e que servem de mote ao discurso sobre a deterioração do edificado. Não surpreende então que o Centro tenha sido já antes identificado como relevante na topografia do medo, sobretudo associado a pistas contextuais: falta de iluminação, falta de policiamento, incivilidades e desertificação (Machado 2004 [1999]); e a rua de Trás, em particular, descrita como um lugar do imaginário de perigosidade portuense (Rodrigues 2002: 125). É, nesse sentido, que ela é aqui tomada como analisador. Acabamos de ver atrás como as circunstâncias descritas são suscetíveis de ser lidas como insecurizantes. Quando um espaço como a rua de Trás, e esta é exemplificativa de muitas, se disfuncionaliza, se desvitaliza, se desertifica, e só lá permanece determinado tipo de grupos sociais vistos como desfavorecidos, pode gerar-se uma espécie de evitamento da zona.

Se foi antes a rua de trás do muro (muralha), hoje poder-se-ia chamar-lhe a rua de trás dos Clérigos, artéria emblemática do Centro. Dos seis quarteirões que a compõem, dois são partilhados com a rua dos Clérigos e constituem fachadas cegas, isto é, traseiras/armazéns de lojas dessa rua, frequentemente sem acesso direto a partir da rua de Trás. De salientar a proximidade geográfica de um dos símbolos mais marcantes da cidade - a torre dos Clérigos -, bem como da Cadeia da Relação, e de uma mancha de animação noturna. É, no entanto, a rua dos Clérigos a que oferece maior contraste, em termos do tipo de comércio, do tipo de visitantes, do tipo de residentes e de outras pistas ecossociais. Se a rua de Trás é estreita, pouco iluminada de dia ou de noite, de pendente acentuada, com edifícios devolutos e lixo por recolher, a rua dos Clérigos, espaço comercial e percurso clássico, espelha a dignidade da rua central, marcada por monumentos de exceção, ampla e cuidada, a desembocar na avenida dos Aliados.

A entrada na rua de Trás, em particular quando o acesso utilizado se faz a partir da Baixa, proporciona uma profunda impressão de contraste em termos da experiência de rua. Para essa impressão contribuem diversos elementos, sendo o mais imediato a polissensorialidade, a profusão de estímulos que apelam aos vários sentidos, parte deles marcas de apropriação daquele espaço: a sonoridade, os cheiros, as imagens que transportam para um lugar distante 
do frenesim da Baixa. Os cães com coleira que circulam livremente, os estendais e o volume elevado da música, o palavrão no fim de cada frase, vernáculo típico, o barulho agora mais distante dos carros, os cheiros vindos das cozinhas, o odor a "ganza" no cimo da rua, durante a noite sempre os mesmos carros estacionados nos mesmo sítios, as pessoas de idade à janela, outras sentadas na soleira das portas.

A observação direta permite apreender uma primeira singularidade: a ausência de outros que não os residentes. Nos quarteirões mais próximos do largo da Cordoaria, é raro observarem-se em trânsito, com exceção dos turistas ocasionais, utilizadores da cidade mais ampla. Esta circunstância, juntamente com outras que se descrevem depois, cria uma impressão de enclave, de espaço que, de tão apropriado, se torna privado, transformando o visitante num forasteiro.

Uma segunda particularidade, também mais premente nos quarteirões de cima, prende-se com o controlo social informal posto em marcha através de diversos mecanismos. Distinguem-se dois que podem ser lidos como “arranjos e pedaços" (Magnani 2002). O comércio local, primeiro, funciona em estreita associação com a rua, assegurando uma observação permanente de quem passa e revelando uma malha social apertada, pouco porosa para o exterior. Descer a rua implica cumprimentar o sapateiro, o alfaiate, o merceeiro, a prostituta. Encontrar alguém que se procure não exige mais do que uma pergunta em qualquer um destes pontos - a informação é sempre dada com precisão. Neste sentido, o "arranjo" na paisagem corresponde ao comportamento coletivo dos atores, que apresenta padrões e sugere a responsabilidade desses atores pela dinâmica quotidiana da rua.

Depois, de entre os grupos informais, que correspondem a um tipo específico de ocupação, regista-se a presença de um grupo de jovens que se posiciona mesmo à entrada da rua. "Gunas" na fala dos habitantes mais recentes, é-lhes atribuído o hábito de "fumar charros" e, mais pontualmente, a responsabilidade pela sua venda. A entrada da rua configura um "pedaço" que, entre outras coisas, constitui um formato peculiar de sociabilidade e de apropriação do espaço. Trata-se, contudo, de um marcador territorial suscetível de ser lido como ameaçador, já que o comportamento exibido varia entre o amigável e o provocador. A sua posição à entrada na rua, a mais confortável por ser a descer, próxima dos transportes públicos, parece funcionar como um filtro, obstáculo à decisão de tomar este como um trajeto habitual.

Finalmente, a par da ocorrência frequente de conflitos na rua, estes jovens (bem como outras figuras que integram outros pedaços adjacentes - em contiguidade espacial) constituem sinais da desordem. Frequentemente surgidos no contexto de alguns agregados familiares, os conflitos são trazidos para o âmbito da rua, fazendo do espaço público como que um prolongamento do privado. 
Se é de esperar que, ao desvitalizarem-se, os lugares sofram um enfraquecimento do controlo social informal - aquele que resulta das interações quotidianas entre residentes e desconhecidos, da vigilância espontânea produzida pelas redes de vizinhança e pelos sentimentos de pertença do espaço -, somos obrigados a concluir que a rua de Trás não se desvitalizou o suficiente para gerar essas consequências. Sob a pressão destes fatores ecológicos, os centros, tendo o mesmo espaço que tinham antes, têm contudo menos lugares. O lugar é um espaço de reconhecimentos, de interações quentes, de pertenças e apropriações. Há lugares que, ocupando pouco espaço físico, têm um imenso espaço psicológico. Se o sentido do lugar, na nossa unidade de estudo, permanece, tal não exclui a presença de signos da crise urbana. É, portanto, como se a rua de Trás produzisse dois fenómenos: o de ser lugar, de ter pedaços e arranjos para quem aí vive, e o de ser espaço de evitamento para quem o olha de fora.

\section{Espaço mediático}

O Observatório Permanente de Segurança do Porto deu, na segunda metade dos anos 90, atenção ao discurso dos meios de comunicação social enquanto fornecedores de "propostas de realidade" em torno da cidade insegura. Tal discurso é um indutor de medo nos seus habitantes? O que os trabalhos encontraram foi uma resposta afirmativa (Manita 1997). Nos relatos dos sujeitos sobre as figuras que induzem receio ou medo constata-se que estas estão presentes através de mecanismos que não o da perceção direta e quotidiana do cidadão. Exemplifiquemos: na altura, estava a acontecer com uma certa repetitividade uma série de rebentamentos de bombas em Espanha. Vários sujeitos, solicitados a produzir uma narrativa acerca das coisas que receavam, disseram temer bombas... Surgia também a figura do cigano como suscetível de provocar medo.

Ora, não se constata que os ciganos estejam especialmente envolvidos no crime predatório, justamente aquele que a literatura indica como mais relacionado com o sentimento de insegurança. Eram, isso sim, noticiados como estando envolvidos com os mercados de drogas, implantados nas zonas relegadas da cidade. Constata-se, por outro lado, que as figuras associadas às drogas são também indutoras de medo, tal como os "bairros sociais degradados", habitualmente noticiados como importantes locais de consumo e tráfico. E estes são, na esfera mediática, associados ao crime predatório... Ou seja, as notícias propõem uma espécie de nebulosa de factos que acabam por, através de vários tipos de associações, ser percecionados como estando todos relacionados entre si.

Isolemos agora dois crimes que foram muito mediatizados no último ano em Portugal - e, no caso dum deles, mesmo internacionalmente. Um é aquele que ficou conhecido como "caso Maddie", a menina inglesa que desapareceu num complexo hoteleiro no Algarve a 3 de maio de 2007; outro é o "caso noite 
branca", assim batizado pela polícia judiciária para designar as investigações em torno de uma sucessão de homicídios de indivíduos ligados a estabelecimentos de diversão noturna no Porto que durou vários meses entre 2007 e 2008.

O "caso Maddie" revela bem as ambiguidades do terreno em que se vai constituindo o sentimento de insegurança. Em primeiro lugar, a ambiguidade em relação ao que realmente aconteceu: rapto ou crime de sangue? Rapto perpetrado por uma rede de pedofilia ou crime de sangue a acontecer no próprio apartamento onde a criança estava? E, nesse caso, quem o cometeu? Os próprios pais? Por negligência ou voluntariamente? Enfim, não sabemos, está por esclarecer.

Outra ambiguidade: qual é a eficácia da polícia? Para que serviram as infindáveis investigações? Depois da maratona de reportagens sobre todos os trâmites que envolveram inúmeros episódios e protagonistas tanto em Portugal como em Inglaterra, pairava a impressão de que, afinal, o território das instâncias que se destinam a proteger-nos é tão escorregadio como o do próprio sentimento de insegurança... O que está em causa na imagem projetada mediaticamente é a capacidade que a polícia e as instâncias judiciais têm para nos proteger da criminalidade. Seria facilmente evidenciável como, a seguir a factos criminais especialmente inquietantes para a opinião pública, é habitual terem lugar operações policiais cuja envergadura tem de imediato repercussão nos meios de comunicação, numa espécie de reposição simbólica do seu papel e, por essa via, de reafirmação do poder dos mecanismos que garantem a ordem social.

Refira-se de passagem o último exemplo do que acabamos de afirmar: no verão de 2008, atos de violência entre moradores da Quinta da Fonte, um bairro de realojamento na Grande Lisboa, foram fortemente mediatizados, passando com insistência imagens de grupos de indivíduos em luta, disparando armas de fogo em plena rua. O debate subsequente incidiu no "barril de pólvora" que se tem vindo a preparar nas periferias desqualificadas, no modo como (não) estão a ser integradas outras culturas e etnias, na (in)eficácia policial no "controlo de marginais", etc. Passados poucos dias, as forças policiais do Porto e de Lisboa efetuaram rusgas de grandes proporções em alguns do principais bairros, tão fortemente mediatizadas como já haviam sido os episódios de violência. Esta sequência em que desvio e reposição simbólica da ordem se sucedem como representação mediática constitui uma espécie de estrutura que encontramos a propósito de muitos outros acontecimentos do mesmo tipo nos últimos anos.

O elemento que queríamos destacar no "caso Maddie" é o do profundo desfasamento entre o alarme social que a sua exploração mediática gerou e a pouca representatividade deste tipo de ocorrência no conjunto da criminalidade. É necessário aprofundar o efeito da hiper-representação de crimes de 
grande impacte emocional mas de baixa probabilidade sobre o sentimento de insegurança. No caso em análise, não custa lançar a hipótese de que este se instalou em pleno na faixa etária infantil, que passou a temer ainda mais as furtivas figuras que ameaçam levar meninos...

Esta hiper-representação está igualmente presente no "caso noite branca". Faça-se, a seu respeito, um pequeno exercício: uma análise do conjunto de notícias em que nós próprios interviemos, na qualidade de especialistas do comportamento desviante. Com efeito, ao longo dos vários meses em que se foram sucedendo mortes relacionadas com o caso, fizemos intervenções na rádio (Antena 1, TSF, Rádio Renascença, Rádio Clube Português), na televisão (RTP) e nos jornais (Público, Diário de Notícias, O Diabo). Que questões nos eram colocadas? O que revelavam elas relativamente à construção do sentimento de insegurança? As perguntas dos jornalistas dividem-se, em traços largos, em três categorias: a que procura causas (por que é que está a acontecer esta onda de violência?), a que identifica consequências (isto faz aumentar o sentimento de insegurança nas populações?), a que busca medidas (o que deve fazer-se? Como devem os poderes públicos reagir?).

A narrativa gira em torno da sofisticação dos atores do crime, capazes de se associar (parece haver grande premeditação e planeamento), e da violência, inabitual para o nosso país (um dos homicídios teve contornos particularmente violentos); girou também sobre a dificuldade das polícias em enfrentar uma criminalidade que cresce em meios enquanto estes são insuficientes nas forças da ordem; e finalmente girou em torno da detenção e prisão preventiva de alguns suspeitos, tendo sido um deles, líder do "gangue da Ribeira", objeto de grande destaque televisivo, com diretos das suas entradas e saídas nas instalações da Polícia Judiciária. Foi lançada em vários momentos a questão de saber se a noite portuense estaria mais insegura, com o cidadão frequentador de espaços de lazer noturnos chamado a pronunciar-se sobre se iria mudar de hábitos, evitar certos locais, enfim, de que modo tencionava reagir ao aumento da violência. ${ }^{7}$

\section{NOTA FINAL}

O sentimento de insegurança parte do medo do crime, cresce em torno dos signos espaciais e sociais de desordem, mas transporta-nos para lá deles: interroga a direção que está a tomar todo o conjunto social. Se há mais delito, como está inscrito dum modo implícito no aumento do sentimento de insegurança, se há mais violência, se os transgressores se mostram mais perigosos, se é mais

$7 \quad$ A estrutura da reportagem faz com que este tipo de testemunhos seja inconclusivo, pois o jornalista procura captar, dum modo aparentemente aleatório, as várias posições possíveis: os que se amedrontam e deixam de sair, os que ficam na dúvida e tomam algumas precauções, os que dizem nada ter a temer... 
provável sermos vítimas, como parece estar subjacente à crença de que estamos mais vulneráveis, que nos diz tudo isto sobre o que está a acontecer às nossas sociedades? O agravamento do crime é o sinal da fragilidade do Estado como figura protetora? A dureza dos criminosos revela a fraqueza dos meios policiais? Enfim, o medo à cidade é o medo do rumo que está a tomar o nosso destino coletivo?

O sentimento de insegurança é um objeto fluido: porque constituído a partir de uma dispersão de acontecimentos, de atores e de contextos, portanto, difícil de delimitar empiricamente, porque faz convergir em seu torno elementos múltiplos da experiência social e da vivência psicológica dos indivíduos. Mais do que um objeto, é um atrator de temas vários, como evidencia a análise do rumor que o alimenta e o faz circular. A fala do crime, como the chama Teresa Caldeira (2000) em A Cidade de Muros, cumpre funções para lá da multiplicidade de factos transgressivos a que alude ou do receio que provocam: é constitutiva do vínculo social, porque é quotidiana e ecoada repetidamente, porque une as pessoas em torno duma mesma experiência do coletivo, porque as põe a falar da ordem, da desordem, da gestão das suas relações, do modo como reagem aos outros, da gestão política da cidade e do país.

O facto de a expressão do sentimento de insegurança estar, tal como fomos demonstrando ao longo do texto, plena de ambiguidades é afinal coerente com as funções que desempenha na economia das relações sociais - porque também saber o que nos está a acontecer é um exercício incerto e ambíguo...

\section{BIBLIOGRAFIA}

ANDRADE, Sérgio, 2008, “Por onde andam os 'brandos costumes?", Jornal de Notícias, 2 de setembro, 12.

CAldeIRA, Teresa, 2000, Cidade de Muros: Crime, Segregação e Cidadania em S. Paulo. São Paulo, Editora 34.

Delgado, Cecília, 1998, Cenário do Delito. Porto, Faculdade de Arquitectura da Universidade do Porto, tese de mestrado em Planeamento e Projeto do Ambiente Urbano.

FATELA, João, 1989, O Sangue e a Rua. Lisboa, Dom Quixote.

FERNANDES, Luís, 1994, "Topografia urbana do medo: os «espaços perigosos»", Revista do Ministério Público, 59: 11-27.

— , 2004, "Bases ecossociais do sentimento de insegurança", Educação, Sociedade e Culturas, 21: 93-112.

—, 2006, "O medo à cidade", em Actas do Encontro de Intervenção Social: Saberes e Contextos. Porto, Escola Superior de Educação de Paula Frassinetti, 99-1 10. 
FERNANDES, Luís, e Maria CARVALHO, 2000, "Problemas no estudo etnográfico de objectos fluidos: os casos do sentimento de insegurança e da exclusão social", Educação, Sociedade e Culturas, 14: 59-87.

FONSECA, Ernesto, 1998, Representação Social da Insegurança: Crime e Crise. Porto, Faculdade de Psicologia e Ciências da Educação da Universidade do Porto, tese de mestrado em Psicologia Social.

LAGRANGE, Randy, Kenneth FERRARO, e Michael SUPANCIC, 1992, "Perceived risk and fear of crime: role of social and physical incivilities", Journal of Research in Crime and Delinquency, 29 (3): 311 -334.

MACHADO, Carla, 2004 [1999], Crime e Insegurança: Discursos do Medo, Imagens do Outro. Lisboa, Editorial Notícias.

MAGNANI, José, 2002, "De perto e de dentro: notas para uma etnografia urbana”, Revista Brasileira de Ciências Sociais, 17 (49): 11-29.

MAI, 2008a, Relatório Anual de Segurança Interna: Ano 2007, Gabinete Coordenador de Segurança, Ministério da Administração Interna, disponível em <http://www.mai.gov. pt/data/documentos/Relatorios\%20Seguranca\%20Interna/RASI2007_Versao-Parlamento.pdf $>$.

— 2008 b, "Portugal: o 9. ${ }^{\circ}$ país mais seguro do mundo", Ministério da Administração Interna, disponível em <http://opiniao.mai-gov.info/2007/05/31/portugalo-9\%c2\%bapais-mais-seguro-do-mundo/>.

MANITA, Celina, 1997, "Insegurança e criminalidade nos media: narrativas da imprensa diária”, em Insegurança Urbana na Cidade do Porto: Estudos Interdisciplinares, vol. III. Porto, Observatório Permanente de Segurança, não publicado.

MANITA, Celina, e Carla MACHADO, 1999, "Percepções e figuras do medo na cidade do Porto: 2. ${ }^{\circ}$ inquérito sobre insegurança urbana”, Insegurança Urbana na Cidade do Porto: Estudos Interdisciplinares. Porto, Centro de Ciências do Comportamento Desviante, Faculdade de Psicologia e Ciências da Educação, Universidade do Porto, vol. 3, não publicado.

NEVES, Tiago, e Luís FERNANDES, 1999, “Periferias urbanas, sentimento de insegurança e controlo social: relatório do projecto 'Insegurança Urbana na Cidade do Porto: Estudos Interdisciplinares'”, coord. Cândido da Agra.

PAIN, Rachel, 2000, "Place, social relations and the fear of crime: a review", Progress in Human Geography, 24 (3): 365-387.

RODRIGUES, Cláudia, 2002, O Porto Desigual e a Transação entre Personagens e Lugares: O Centro Histórico, a "Ilha" e o Bairro Social. Lisboa, Instituto Superior de Psicologia Aplicada, tese de mestrado em Psicologia Ambiental.

SANTOS, Eduardo, 1997, A Cidade e o Crime: Uma Perspectiva Dinâmica. Porto, Faculdade de Psicologia e Ciências da Educação da Universidade do Porto, tese de doutoramento.

SKOGAN, Wesley, 1990, Disorder and Decline. Nova Iorque, The Free Press.

— ncjrs.gov/pdffiles 1/170610-2.pdf> (acesso em 20/05/2010).

TAVARES, Cynthia, e Geoffrey THOMAS, 2007, "Crime and criminal justice", Statistics in Focus: Population and Social Conditions, 15/2007, European Communities, disponível em <http://epp.eurostat.ec.europa.eu/cache/ITY_OFFPUB/KS-SF-07-015/EN/KS-SF-07015-EN.PDF>. 
TAYLOR, Ralph, 1989, “Toward an environmental psychology of disorder: delinquency, crime, and fear of crime”, em Handbook of Environmental Psychology. Nova Iorque, John Wiley and Sons.

VAZ, Maria João, 1998, Crime e Sociedade: Portugal na Segunda Metade do Século XIX. Oeiras, Celta Editora.

—, 2006, "A introdução da polícia civil em Portugal: entre projectos e realidades, os equívocos de uma política de segurança”, em Pedro Almeida e Tiago Marques (orgs.), Lei e Ordem: Justiça Penal, Criminalidade e Polícia, Séculos XIX-XX. Lisboa, Livros Horizonte.

WODC, 2003, European Sourcebook of Crime and Criminal Justice Statistics - 2003. Haia, Wetenschappelijk Onderzoek en Documentatiecentrum, disponível em < http://www. europeansourcebook.org/esb2_Full.pdf >.

—, 2006, European Sourcebook of Crime and Criminal Justice Statistics - 2006. Haia, Wetenschappelijk Onderzoek en Documentatiecentrum, disponível em <http://www.europeansourcebook.org/esb3_Full.pdf>.

Where is the feeling of insecurity? Social and scientific questions concerning the fear of the city - Luís Fernandes - Faculdade de Psicologia e Ciências da Educação da Universidade do Porto, Portugal • jllf@fpce.up.pt •• Ximene Rêgo • Bolseira de doutoramento da Fundação para a Ciência e a Tecnologia, Portugal • ximene@gmail.com

The public debate has taken the issues of (in)security, creating fixed images of what is crime and violence in Portugal. Images full of ambiguity, not only for their paradoxes that the scientific community has shown to be constitutive of the feeling of insecurity, but also by the profusion of utterances of the various social actors on the scene - from the media to the instances of formal control. Here, we follow the shift from the fear of city, with the advent of modern dangers, to the feeling of insecurity, which is the subject of social sciences. We analyse thereafter two determinants of its construction: its eco-social elements - from an ongoing study at the Centre of Porto, and its public dimension - from recent cases with a high media exposure. We expect thus to contribute to a reduction of the degree of ambiguity that has marked the public expression of this subject.

KEYWORDS: feeling of insecurity, crime, mass media, ethnography. 